\title{
Technical Note: An implementation of the dry removal processes DRY DEPosition and SEDImentation in the Modular Earth Submodel System (MESSy)
}

\author{
A. Kerkweg, J. Buchholz, L. Ganzeveld, A. Pozzer, H. Tost, and P. Jöckel \\ Air Chemistry Department, Max-Planck Institute of Chemistry, P.O. Box 3060, 55020 Mainz, Germany \\ Received: 8 June 2006 - Published in Atmos. Chem. Phys. Discuss.: 24 July 2006 \\ Revised: 6 October 2006 - Accepted: 11 October 2006 - Published: 12 October 2006
}

\begin{abstract}
We present the submodels DRYDEP and SEDI for the Modular Earth Submodel System (MESSy). Dry deposition of gases and aerosols is calculated within DRYDEP, whereas SEDI deals with aerosol particle sedimentation. Dry deposition velocities depend on the near-surface turbulence and the physical and chemical properties of the surface cover (e.g. the roughness length, soil pH or leaf stomatal exchange). The dry deposition algorithm used in DRYDEP is based on the big leaf approach and is described in detail within this Technical Note. The sedimentation submodel SEDI contains two sedimentation schemes: a simple upwind zeroth order scheme and a first order approach.
\end{abstract}

\section{Introduction}

The current knowledge about the dry deposition process is relatively poor (Wesely and Hicks, 2000), as dry deposition has only been measured for a relatively small set of species (e.g., $\mathrm{O}_{3}, \mathrm{NO}_{\mathrm{x}}, \mathrm{HNO}_{3}, \mathrm{SO}_{2}$ and sulphate) and that mostly in rather short intensive field campaigns. In addition, identification and quantification of the role of the various controlling biological, chemical and physical processes poses large challenges to the experimentalists. Consequently, a commonly applied approach to estimate the dry deposition velocities (needed to calculate the dry deposition flux) is that proposed by Wesely (1989): The solubility and reactivity of a tracer is used to estimate its dry deposition velocity relative to those of ozone and sulfur dioxide whose dry deposition velocities are relatively well known. Our algorithm is adopted from prior work of Ganzeveld and Lelieveld (1995) and Ganzeveld et al. (1998). The latter already included particle sulphate dry deposition based on a predefined particle-size distribution. This was expanded to deal with aerosol dry deposition for aerosol

Correspondence to: A. Kerkweg

(akerkweg@mpch-mainz.mpg.de) distributions calculated online (Ganzeveld et al., 2006). This approach was used for the first time by Stier et al. (2005). Often, publications illustrate only the idea of an approach for the implementation of a distinct process, but crucial details of the technical realisation are omitted. This Technical Note is dedicated to describe the details for the MESSy submodels DRYDEP and SEDI for the sake of reproducibility. Every mathematical relationship required for the implementation is given in this article to set the reader into the position to understand and modify the code, if needed. Section 2.1.1 describes the dry deposition algorithm for trace gases, whereas Sect. 2.1.2 contains details about the aerosol dry deposition scheme. The sedimentation process is often treated together with dry deposition. But two major differences between these two processes render it useful to simulate them separately.

1. Dry deposition is only applied in the lowermost model layer, whereas sedimentation takes place within the whole vertical domain.

2. Sedimentation is a significant sink process for aerosol particles (as they carry enough mass), whereas sedimentation of trace gases is negligible.

The MESSy coding standard presents an additional reason for the separation of these two processes (Jöckel et al., 2005), as it implies the idea that every specific process is coded as a separate, independent entity, i.e. as a submodel which can be switched on/off individually.

The calculation of the sedimentation velocities is based on an approach usually found in textbooks (see Sect. 2.2). The Subsects. 2.2.1 and 2.2.2 describe the zeroth order and first order scheme, respectively. Section 2.3 focuses on the implementation of the two submodels into the MESSy system and Sect. 3 shows some examples.

Published by Copernicus GmbH on behalf of the European Geosciences Union. 


\section{Submodel description}

DRYDEP and SEDI are implemented as independent submodels in adherence to the MESSy standard as described by Jöckel et al. (2005). This also implies a good portability due to the coding in standard Fortran95 (ISO/IEC-1539-1). No compiler-specific language extensions are used. The code quality has been further checked by application of the Fortran analyser forcheck (http://www.forcheck.nl/).

Applying the dry deposition and/or sedimentation process to additional tracers does not require any recoding, only the definition of the Henry's Law coefficient and a reactivity factor is necessary.

In the following the units of the variables in each equation within this Technical Note are explicitly given, even if the physical correctness of the equation is not dependent on the unit. This is because this Technical Note gives an overview of the implementation of the dry deposition and the sedimentation process within the MESSy submodels DRYDEP and SEDI and thus the equations as implemented in these submodels (including unit conversions) are given.

\subsection{DRY DEPosition (DRYDEP)}

The representation of the dry deposition process is based on the algorithm used for online calculation of dry deposition velocities according to the big leaf approach in ECHAM3 (DKRZ, 1992) and ECHAM4 (Roeckner et al. (1996); http://www.mpimet.mpg.de/en/wissenschaft/ueberblick/ atmosphaere-im-erdsystem/globale-klimamodellierung/ echam.html) as published by Ganzeveld and Lelieveld (1995) and Ganzeveld et al. (1998).

The core of the DRYDEP submodel is based on parts of the submodel EMDEP (Ganzeveld et al., 2006). The modular structure of MESSy allows for the implementation of different parameterisations of the same process in different submodels (see Jöckel et al., 2005).

EMDEP is a so-called "development" submodel, which is continuously updated. As DRYDEP contains evaluated and well documented parameterisations of dry deposition it provides a suitable benchmark for atmospheric chemistry studies with MESSy that do not primarily focus on the surface/air exchange processes, but which nevertheless require those processes to be taken into account.

\subsubsection{DRY DEPosition of trace gases}

The dry deposition flux $F_{\text {dep }}(X)\left(\mathrm{kg} /\left(\mathrm{m}^{2} \mathrm{~s}\right)\right)$ is given by

$F_{\text {dep }}(X)=\mu_{g}(X) \times \frac{M(X)}{M_{\text {air }}} \times \frac{\Delta p}{g \Delta z} \times v_{d}(X)$

with $\mu_{g}(X)$ being the gas phase mixing ratio of species $X$ in mol/mol and $M(X)$ and $M_{\text {air }}$ the molar mass of species $X$ and dry air (in $\mathrm{kg} / \mathrm{mol}$ ), respectively. $g$ is the gravitational acceleration $\left(\mathrm{m} / \mathrm{s}^{2}\right), \Delta p$ and $\Delta z$ are the layer thicknesses in $\mathrm{Pa}$ and $\mathrm{m}$, respectively. The dry deposition velocity
$v_{d}(X)$ of a trace gas $X$ (in $\mathrm{m} / \mathrm{s}$ ) depends on the aerodynamic resistance $R_{a}$, the quasi-laminar boundary layer resistance $R_{q b r}(X)$, and the surface resistance $R_{S}(X)$ (all resistances are in units of $\mathrm{s} / \mathrm{m})$ :

$v_{d}(X)=\frac{1}{R_{a}+R_{q b r}(X)+R_{s}(X)}$,

where $R_{a}$ is a function of the physical state of the atmosphere, $R_{q b r}(X)$ is controlled by molecular diffusion and $R_{S}(X)$ depends on the chemical, physical and biological properties of the surface. The resistances are given as follows:

1. The aerodynamic resistance $R_{a}$ :

$R_{a, t}=\frac{1}{u_{\star, t} \kappa}\left[\log \left(\frac{z}{z_{0, m}}\right)-\Phi_{h, t}\right]$

with $u_{\star, t}$ being the friction velocity in $\mathrm{m} / \mathrm{s}, \kappa=0.4$ being the dimensionless von Karman constant, $z$ the reference height, and $z_{0, m}$ the momentum roughness length (both in $\mathrm{m}$ ). The dimensionless stability function $\Phi_{h, t}$ depends on the Monin-Obukhov-Length, and thus on the horizontal wind speed and the temperature profile.

In this algorithm four different surface types $(t)$ are distinguished:

- veg for vegetation

- slsn for bare soil/snow

- ice for sea ice/snow and

- wat for water.

2. The quasi-laminar boundary layer resistance $R_{q b r}$ :

$R_{q b r, t}(X)=\ln \left(\frac{z_{0, m}}{z_{0, X}}\right) \frac{1}{u_{\star, t} \kappa}\left(\frac{S c}{P r}\right)^{2 / 3}$,

where $z_{0, m}$ and $z_{0, X}$ are the surface roughness lengths (in $\mathrm{m}$ ) of momentum and a trace gas $\mathrm{X}$, respectively, $\mathrm{Pr}$ is the Prandtl number (here assumed to be 0.72 ), and $S c$ the Schmidt number, which is defined as the ratio of kinematic viscosity of air to the molecular diffusivity of a trace gas. Usually the influence of $R_{q b r}(X)$ is small compared to $R_{a}$ and $R_{S}(X)$.

3. The surface resistance $R_{S}(X)$ :

$R_{S}(X)$ depends on the surface type and on the properties of the respective trace gas. In DRYDEP the calculation of the surface resistance follows the scaling approach of Wesely (1989) for all gases that are not explicitly considered in the studies of Ganzeveld and Lelieveld (1995) and Ganzeveld et al. (1998). As the dry deposition velocities of ozone and sulfur dioxide are relatively well known, the approach of Wesely (1989) uses these two 

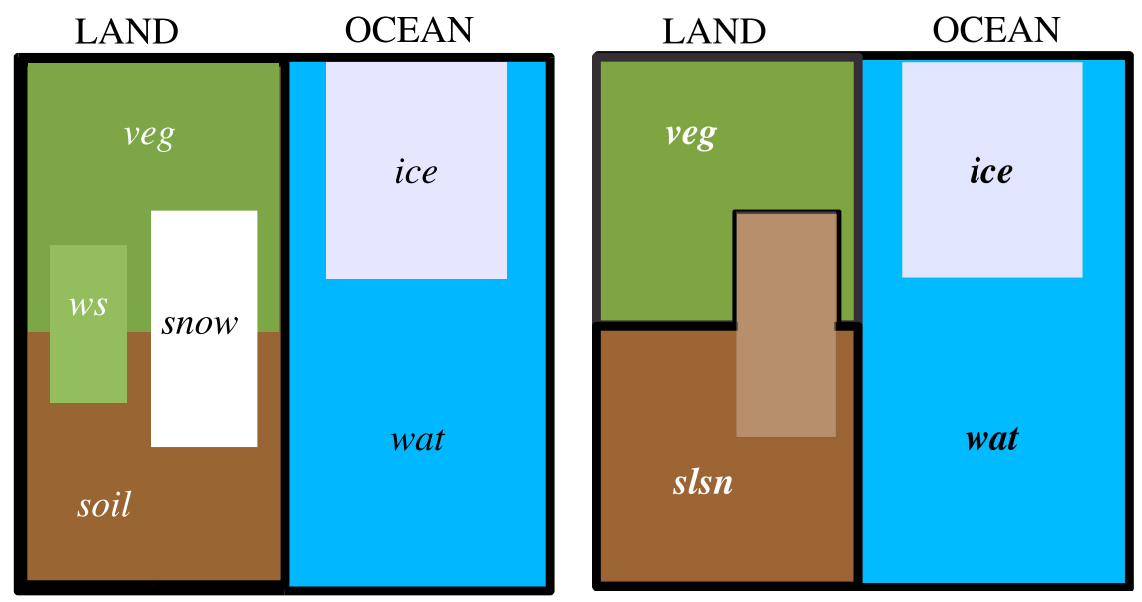

Fig. 1. Illustration of the index definition for the surface resistances $R_{S}$ (left) and the aerodynamic resistances and the quasi-laminar boundary layer resistances ( $R_{a}$ and $R_{q b r}$, right). For $R_{S} 6$ surface types are distinguished, whereas only 4 are taken into account for $R_{a}$ and $R_{q b r}$. For the latter the moisture content of the soil and the vegetation $(w s)$ is ignored. Vegetation covered by snow is considered as part of the surface type slsn.

trace gases to scale all others. $\mathrm{O}_{3}$ and $\mathrm{SO}_{2}$ represent reactive non-soluble and non-reactive soluble trace gases, respectively. The effective Henry's Law coefficient $H$ (in $\mathrm{mol} /\left(\mathrm{dm}^{3} \mathrm{~atm}\right)$ ) is used as a measure for the solubility of a trace gas, whereas the reactivity of a trace gas is given by a so-called reactivity coefficient $s_{\text {reac. }}$. The empirical formulas taken from Wesely (1989) are only valid if $s_{\text {reac }}$ has values of $1,0.1$ or 0 . Here, 1 indicates a trace gas similarly reactive as ozone, whereas 0 stands for a nearly non reactive gas. 0.1 is for slightly reactive gases. For more details about this approach the reader is referred to Wesely (1989). Unlike $R_{a}$ and $R_{q b r}$, a universal formula does not exist for the surface resistances. The individual equations are given in Appendix A2. In grid boxes over land, four different land types are taken into account:

- the snow/ice covered fraction (index snow)

- bare soil (index soil),

- vegetation (index veg) and

- the water in the wet skin reservoir (index ws) (i.e., the fraction of the vegetation and bare soil wetted due to rain fall interception and dew fall).

Figure 1 illustrates the different types of resistances: The types soil and snow are only distinguished for the surface resistances (left). For the aerodynamic resistances and the quasi-laminar boundary layer resistances these two types are combined within the type slsn (right). This simplification is justified with the assumption of comparable roughness for bare soil and snow covered surfaces. Additionally, the difference between wet skin reservoir (index ws) and the dry overgrown surface (index veg) or the dry bare soil (index soil) is only made for the surface resistance (Fig. 1, left). For $R_{a}$ and $R_{q b r}$ only the types slsn and veg are distinguished (Fig. 1, right).

Over the ocean, a distinction is made between the open ocean (index wat) and the sea ice covered fraction $\left(f_{\text {ice }}\right)$. The surface resistance of the latter is equal to the surface resistance for snow covered regions over land $\left(R_{s, \text { ice }}=R_{s, \text { snow }}\right)$.

The formulas for the calculation of the aerodynamic resistances and the surface resistances are given in Appendix A1 and $\mathrm{A} 2$, respectively.

As the different surface properties influence the dry deposition velocities, the actual dry deposition velocity in each grid box is a composition of the individual dry deposition velocities for the different surface types existent in the grid box. First an overall classification of a model grid box as water or land box is applied:

$v_{d}(X)=\left\{\begin{array}{cl}v_{d, \text { land }} & \text { for } \quad f_{\text {land }} \geq 0.5 \\ v_{d, \text { wat }} & \text { for } \quad f_{\text {land }}<0.5\end{array}\right.$,

where $f_{\text {land }}$ is the land covered fraction of a grid box. The dry deposition velocities over land $v_{d, l a n d}$ are determined following

$$
\begin{aligned}
& v_{d, \text { land }}(X)= \\
& f_{\text {snow }} \times\left(R_{a, s l s n}+R_{b q r, s l s n}(X)+R_{s, \text { snow }}(X)\right)^{-1} \\
& \quad+\left(1-f_{\text {snow }}\right) \times\left(1-f_{w s}\right) \times f_{\text {veg }} \\
& \quad \times\left(R_{a, \text { veg }}+R_{b q r, v e g}(X)+R_{s, \text { veg }}(X)\right)^{-1} \\
& +\left(1-f_{\text {snow }}\right) \times\left(1-f_{w s}\right) \times\left(1-f_{\text {veg }}\right) \\
& \quad \times\left(R_{a, s l s n}+R_{b q r, \text { slsn }}(X)+R_{s, \text { soil }}(X)\right)^{-1} \\
& +\left(1-f_{\text {snow }}\right) \times f_{\text {ws }} \\
& \quad \times\left(R_{a, \text { veg }}+R_{b q r, v e g}(X)+R_{s, w s}(X)\right)^{-1}
\end{aligned}
$$




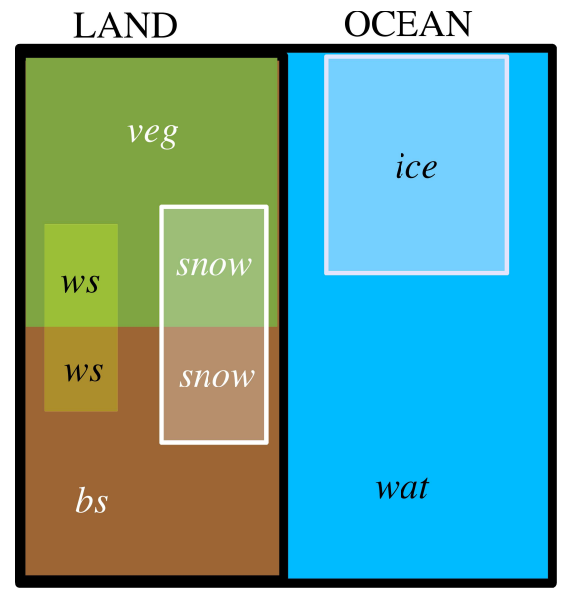

Fig. 2. Illustration of the index definition for the surface fractions within one model grid box. The fractions within each black frame add up to 1 : the ocean fraction $\left(1-f_{\text {land }}\right)$ and the land fraction $f_{\text {land }}$ add up to $1 ; f_{i c e}+f_{w a t}=1 ; f_{v e g}+f_{b s}=1$. The fractions additionally needed for the surface resistances ( $f_{w s}$ and $f_{\text {snow }}$ ) overlap with $f_{v e g}$ and $f_{b s}$. Furthermore it is $f_{w s}+f_{\text {snow }} \leq 1$.

$f_{\text {snow }}$ is the snow fraction, $f_{w s}$ the wet skin fraction and $f_{v e g}$ the fraction of vegetation.

The dry deposition velocity over water $v_{d, w a t}$ is determined by

$$
\begin{aligned}
& v_{d, w a t}(X)= \\
& f_{i c e} \times\left(R_{a, i c e}+R_{q b r, i c e}(X)+R_{s, \text { snow }}(X)\right)^{-1} \\
& +\left(1-f_{\text {ice }}\right) \times\left(R_{a, w a t}+R_{q b r, w a t}(X)+R_{s, w a t}(X)\right)^{-1}
\end{aligned}
$$

where $f_{\text {ice }}$ is the sea ice fraction and $f_{\text {land }}$ is the land fraction. Figure 2 illustrates the sectioning of a model grid box into the different parts described by the indexed fractions.

\subsubsection{Dry deposition of aerosols}

The aerosol dry deposition is also based on the big leaf approach. In contrast to the gas phase dry deposition only three surface types are distinguished:

- vegetation (index veg)

- bare soil and snow (index slsn) and

- water (index wat).

The overall dry deposition velocity $v_{d, p}(X)$ is determined by

$$
\begin{aligned}
v_{d, p}(X) & =\left(f_{\text {snow }}+f_{b s}\right) \times v_{d, p, s l s n}(X) \\
& +\left(1-f_{\text {snow }}\right)\left(1-f_{w s}\right) f_{v e g} \times v_{d, p, v e g}(X) \\
& +\left(1-f_{\text {snow }}\right) f_{w s} \times v_{d, p, v e g}(X) \\
& +f_{\text {ice }} \times v_{d, p, s l s n}(X) \\
& +f_{\text {wat }} \times v_{d, p, w a t}(X) .
\end{aligned}
$$

Here, $f_{\text {snow }}, f_{b s}, f_{\text {wat }}, f_{\text {veg }}, f_{w s}$ and $f_{i c e}$ are the surface fractions of snow, bare soil, water, vegetation, wet skin and ice, respectively. The individual dry deposition velocities (in $\mathrm{m} / \mathrm{s}$ ) are calculated as follows:

$$
\begin{aligned}
& v_{d, p, v e g}(X)=\left(\frac{R_{a, v e g}}{100}+\frac{1}{v_{k d, p, v e g}(X)}\right)^{-1} \\
& v_{d, p, s l s n}(X)=\left(\frac{R_{a, s l s n}}{100}+\frac{1}{v_{k d, p, s l s n}(X)}\right)^{-1} \\
& v_{d, p, w a t}(X)=\left(\frac{R_{a, w a t}}{100}+\frac{1}{v_{k d, p, w a t}(X)}\right)^{-1} .
\end{aligned}
$$

The aerodynamic resistances are the same as in the gas phase dry deposition scheme (see Appendix A1). Appendix B contains the equations for the calculation of the specific dry deposition velocities $v_{k d, p, v e g}, v_{k d, p, s l s n}$ and $v_{k d, p, w a t}$. They depend on the particle radius $r_{p}$, the particle density $\rho_{p}$ and - for modal distributions - on the radius standard deviation $\sigma_{p}$ of the mode (see also Ganzeveld et al., 2006).

For the dry deposition velocity calculation for particle number mixing ratios $(1 / \mathrm{mol})$ the ambient number median radius $r_{p, a}$ as provided by the aerosol models is taken directly, whereas for the dry deposition of aerosol compounds (e.g. $\mathrm{SO}_{4}^{2-}, \mathrm{Na}^{+}$or $\mathrm{Cl}^{-}$) the mass mean radius $r_{p, m m}$ is used, i.e.:

$r_{p}(k)=\left\{\begin{array}{cl}r_{p, a}(k) & \text { for bins and numbers } \\ r_{p, a}(k) e^{3.5 *\left(\ln \sigma_{p}(k)\right)^{2}} & \text { for compounds of modes. }\end{array}\right.$

Since aerosol modes are described as lognormal distributions, the centre of mass of a mode is associated with the mass mean radius and not with the mass median radius. In a distribution of particles with constant density larger particles deposit faster than smaller particles. Thus it is more appropriate to use the mass mean radius for the dry deposition of the mass instead of the median radius.

The aerosol compound dry deposition flux $F_{\mathrm{dep}, c}$ in units of $\mathrm{kg} /\left(\mathrm{m}^{2} \mathrm{~s}\right)$ is calculated by

$$
F_{\text {dep }, c}(X)=\mu_{p}(X) \times \frac{M(X)}{M_{\text {air }}} \times \frac{\Delta p}{g \Delta z} \times v_{d, p}(X),
$$

where $\mu_{p}$ is the mixing ratio of an aerosol compound in $\mathrm{mol} / \mathrm{mol}$ and $M(X)$ the molar mass of the aerosol compound (e.g. $0.096 \mathrm{~kg} / \mathrm{mol}$ for $\mathrm{SO}_{4}^{2-}$ ). $g$ is the gravitational acceleration $\left(\mathrm{m} / \mathrm{s}^{2}\right), \Delta p$ and $\Delta z$ the layer thicknesses in $\mathrm{Pa}$ and $\mathrm{m}$, respectively.

The particle number dry deposition $F_{\text {dep }, p}$ (in $\frac{\text { particle }}{\text { mol }} \frac{\mathrm{kg}}{\mathrm{m}^{2} \mathrm{~s}}$ ) of an aerosol size bin/mode is given by

$F_{\text {dep }, p}(X)=\mu_{p}(X) \times \frac{\Delta p}{g \Delta z} \times v_{d, p}(X)$.

$\mu_{p}(X)$ is here the number mixing ratio in $1 / \mathrm{mol}$.

\subsection{Aerosol SEDImentation (SEDI)}

In contrast to dry deposition, which occurs in the lowermost part of the atmosphere only, sedimentation happens throughout the atmosphere. It describes the settling process due to 
gravity, thus it is negligible for gases, but it is an important sink for particles.

The formulas applied for the calculation of the terminal sedimentation velocity are based on the theory of aerosol sedimentation (see for example Pruppacher and Klett (1997), page 451 ). The terminal sedimentation velocity $v_{t}$ (in $\mathrm{m} / \mathrm{s}$ ) is given by the Stokes velocity $v_{\text {Stokes }}$ modified by the Cunningham-slip-flow correction $f_{\mathrm{Csf}}$ and the Slinn factor $f_{\text {Slinn: }}$ :

$v_{t}=v_{\text {Stokes }} \times f_{\text {Slinn }} \times f_{\text {Csf }}$

with

$$
\begin{aligned}
v_{\text {Stokes }}= & \frac{2}{9}\left(\rho_{p}(k)-\rho_{\text {air }}\right) \frac{g}{\eta_{d}} r_{p}(k)^{2} \\
f_{\text {Csf }}= & 1+1.257 \frac{\lambda_{\text {air }}}{r_{p}(k)} \\
& +0.4 \frac{\lambda_{\text {air }}}{r(k)} \exp \left(\frac{-1.1 r_{p}(k)}{\lambda_{\text {air }}}\right)
\end{aligned}
$$

$$
f_{\text {Slinn }}=\left\{\begin{array}{cl}
1 & \text { for bins and numbers } \\
\sigma_{p}(k)^{2 l n \sigma_{p}(k)} & \text { for lognormal modes }
\end{array}\right.
$$

where $k$ denotes the respective aerosol mode or bin, $\sigma_{p}(k)$ is the radius standard deviation, $\rho_{p}(k)$ the aerosol density (in $\mathrm{kg} / \mathrm{m}^{3}$ ) and $r_{p}(k)$ the ambient radius (in $\mathrm{m}$ ) of aerosol mode $k$. $\eta_{d}$ denotes the dynamic viscosity of air (in $\left.\mathrm{kg} /\left(\mathrm{m}^{2} \mathrm{~s}\right)\right), g$ the gravitational acceleration (in $\mathrm{m} / \mathrm{s}^{2}$ ) and $\lambda_{\text {air }}$ the mean free path of air molecules (in $\mathrm{m}$ ). $v_{\text {Stokes }}$ is the sedimentation velocity of spheres in $\mathrm{m} / \mathrm{s}$. The Cunningham-slip-flow factor corrects for aerodynamic differences between ideal spheres and real non-spherical particles. In case of lognormal distributions the particle radius varies over a wide range. As the mean sedimentation velocity of all particles of a lognormal mode is larger than the sedimentation velocity for a particle of the mean radius, a correction factor has to be applied. This is the meaning of the Slinn factor $f_{\text {Slinn }}$ (Slinn and Slinn, 1980).

There are different possibilities to calculate the change in the tracer concentration due to sedimentation with one terminal velocity. SEDI comprises two schemes: a zeroth order scheme and a first order scheme.

2.2.1 Sedimentation scheme of zeroth order / Simple upwind scheme

The sedimentation scheme of zeroth order is a simple upwind scheme. The assumption is made that all particles of one grid box are equally distributed with height. The fraction $\xi(i)$ (in $1 / \mathrm{s}$ ) of particles falling out of one box $i$ per time step $\Delta t$ is simply determined by the geometric vertical extension of the grid box $\Delta z(i)$ (in $\mathrm{m}$ ) and the terminal velocity $v_{t}$ (in $\mathrm{m} / \mathrm{s}$ ):

$\xi(i)=v_{t} \frac{\Delta t}{\Delta z(i)}$.

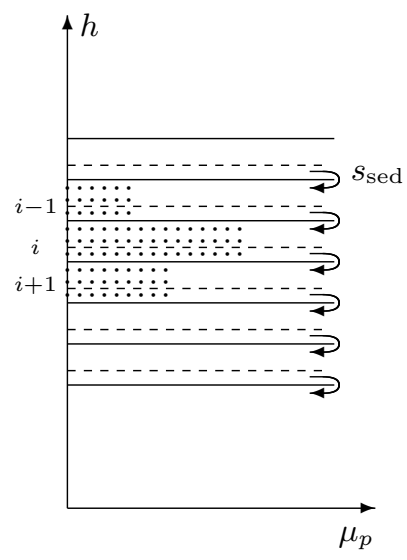

Fig. 3. Simple upwind scheme sedimentation assumes that if particles fall a distance $s_{\text {sed }}$, all particles from the lowermost layer of thickness $s_{\text {sed }}$ of a grid box reach the next grid box below.

In the sedimentation scheme of zeroth order the amount of particles falling down from one box into the next box below can also be associated with a cuboid moved from the lowest part of the higher box to the highest part of the box below. $s_{\text {sed }}$ in Fig. 3 (which shows a cross section of a column of boxes) is the height of this moving cuboid. Multiplication by the mixing ratio $\mu_{p}$ of these particles in the respective box leads to a tracer tendency due to sedimentation out of this box:

$$
\left.\frac{\Delta \mu_{p}(i)}{\Delta t}\right|_{\text {out }}=\xi(i) \times \frac{\mu_{p}(i)}{\Delta t}
$$

Particles leaving one box enter the box below, i.e. the incoming flux $F_{\text {in }}$ for box $i$ equals the outgoing flux $F_{\text {out }}$ of the box above $(i-1)$ :

$F_{\text {in }}(i)=F_{\text {out }}(i-1)=\left.\frac{\Delta \mu_{p}(i-1)}{\Delta t}\right|_{\text {out }} \times \frac{\Delta p(i-1)}{g}$

$\Delta p(i)$ is the thickness of the box in pressure units (Pa) and $g$ the gravitational acceleration $\left(\mathrm{m} / \mathrm{s}^{2}\right)$. The incoming flux for the uppermost box is zero.

The tracer tendency for the lower box can be calculated using the incoming flux:

$$
\left.\frac{\Delta \mu_{p}(i)}{\Delta t}\right|_{\text {in }}=F_{\text {in }}(i) \times \frac{g}{\Delta p(i)}
$$

Combining Eq. (19) and Eq. (21) results in the overall tracer tendency in box $i$

$$
\begin{array}{r}
\frac{\Delta \mu_{p}(i)}{\Delta t}=\left.\frac{\Delta \mu_{p}(i)}{\Delta t}\right|_{\text {in }}-\left.\frac{\Delta \mu_{p}(i)}{\Delta t}\right|_{\text {out }} \\
=\left.\frac{\Delta \mu_{p}(i-1)}{\Delta t}\right|_{\text {out }} \times \frac{\Delta p(i-1)}{\Delta p(i)}-\left.\frac{\Delta \mu_{p}(i)}{\Delta t}\right|_{\text {out }}
\end{array}
$$




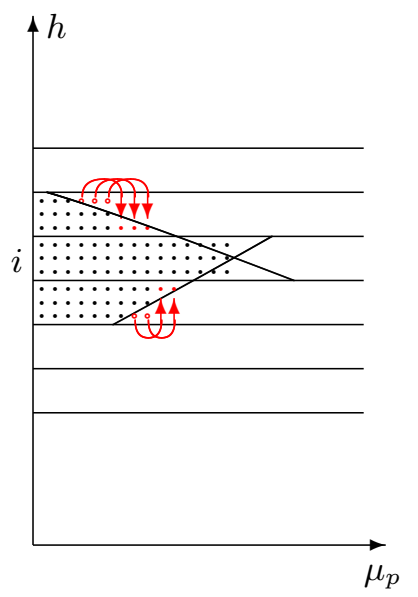

Fig. 4. In the trapezoid/first order scheme, the constant mixing ratios in each grid box (compare Fig. 3) are replaced by first order approximations.

\subsubsection{Sedimentation scheme of first order / Trapezoid} scheme

A possible improvement of the zeroth order sedimentation scheme described in Sect. 2.2.1 is the use of first order polynomials for the vertical profile of the mixing ratio $\left(\mu_{p}\right)$. The sedimentation scheme was developed in the context of the MESSy submodel PSC (a submodel for the simulation of polar stratospheric clouds, see Buchholz, 2005). With the first order scheme, the determination of the changes in the $\mu_{p}$ profile due to sedimentation is no longer based on the $\mu_{p}$ step function shown in Fig. 3. Instead, the amount of the particle substance to move from grid box $i$ downwards into the grid box $i+1$ is calculated by means of a straight line approximation for the $\mu_{p}$ profile in grid box $i$. The advantage of a first order vertical profile compared to the step function used in the simple upwind scheme becomes apparent by considering a local maximum in the vertical profile. Imagine a peak located around box $i$ (see Fig. 4). A step function does not distinguish between those parts of the box $i-1$ or $i+1$ which are near the local maximum and those parts away from it. Straight line approximations for $\mu_{p}$ inside the grid boxes, on the contrary, can reproduce the feature that in the box above $(i-1)$ more aerosol particles are located at the bottom of the box than at the top. Similarly, in box $i+1$, straight line approximations increase $\mu_{p}$ near the top, i.e. near the peak. Consequently, in the first order scheme more particles move from the grid box immediately above the local maximum into the next lower grid box than in the zeroth order simple upwind scheme (see Fig. 3).

The base of the first order scheme are the local straight line approximations for the mixing ratio. A straight line in the $\left(p, \mu_{p}\right)$-plane is defined by the two points $\left(p\left(z_{1}\right), \mu_{p}\left(z_{1}\right)\right)$ and $\left(p\left(z_{2}\right), \mu_{p}\left(z_{2}\right)\right)$, where $z_{1}$ and $z_{2}$ indicate the box indices

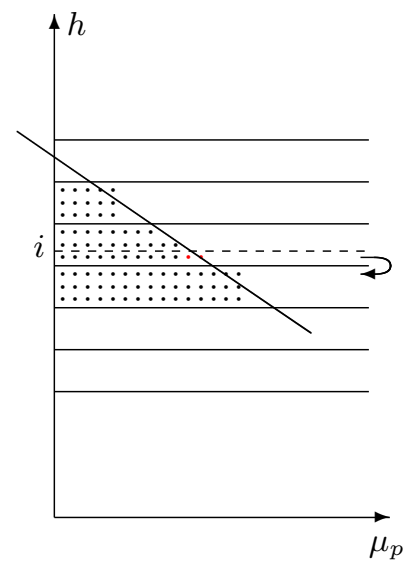

Fig. 5. The linear approximations above a local maximum lead to increased particle transport. The red circles indicate particles which do sediment in the trapezoid scheme but would not sediment in the simple upwind scheme.

which may be $i$ and $i+1$ or $i-1$ and $i$. Its slope is

$m_{1,2}=\frac{\mu_{p}\left(z_{2}\right)-\mu_{p}\left(z_{1}\right)}{p\left(z_{2}\right)-p\left(z_{1}\right)}$

and its intercept is

$b_{1,2}=\mu_{p}\left(z_{1}\right)-\frac{\mu_{p}\left(z_{2}\right)-\mu_{p}\left(z_{1}\right)}{p\left(z_{2}\right)-p\left(z_{1}\right)} p\left(z_{1}\right)$.

The linearly approximated mixing ratio is therefore

$$
\begin{aligned}
\mu_{p}(z)= & \frac{\mu_{p}\left(z_{2}\right)-\mu_{p}\left(z_{1}\right)}{p\left(z_{2}\right)-p\left(z_{1}\right)} p(z) \\
& +\mu_{p}\left(z_{1}\right)-\frac{\mu_{p}\left(z_{2}\right)-\mu_{p}\left(z_{1}\right)}{p\left(z_{2}\right)-p\left(z_{1}\right)} p\left(z_{1}\right) .
\end{aligned}
$$

For the simple upwind scheme, the part of box $i$ from which particles move into the next lower grid box $i+1$ within one model time step corresponds to a rectangle in the $\left(p, \mu_{p}\right)$ plane. Using the straight line approximation for $\mu_{p}(z)$, this rectangle is replaced by a trapezoid (see Figs. 5 and 6).

In mathematical terms, the rectangle in the simple upwind scheme is represented by the product $\mu_{p}(i-1) s_{\text {sed }}(i-1)$.

The area of the corresponding trapezoid in the first order scheme is

$$
\begin{aligned}
A_{\text {trap }}= & \frac{1}{2}\left(\mu_{p}\left(z_{1}\right)+\mu_{p}\left(z_{2}\right)\right) \Delta p_{\text {sed }}(i-1) \\
= & \left(m_{1,2} p\left(z_{1}\right)+b_{1,2}+m_{1,2} p\left(z_{2}\right)+b_{1,2}\right) \\
& \quad \times \frac{1}{2} \times \Delta p_{\text {sed }}(i-1) \\
= & \left(m_{1,2} \frac{p\left(z_{1}\right)+p\left(z_{2}\right)}{2}+b_{1,2}\right) \\
& \times \Delta p_{\text {sed }}(i-1) .
\end{aligned}
$$

The mixing ratios $\mu_{p}\left(z_{1}\right)$ and $\mu_{p}\left(z_{2}\right)$ form the two parallel sides of the trapezoid. $\Delta p_{\text {sed }}(i-1)$ is the height of the trapezoid, which equals the distance in Pa the aerosol particles fall 


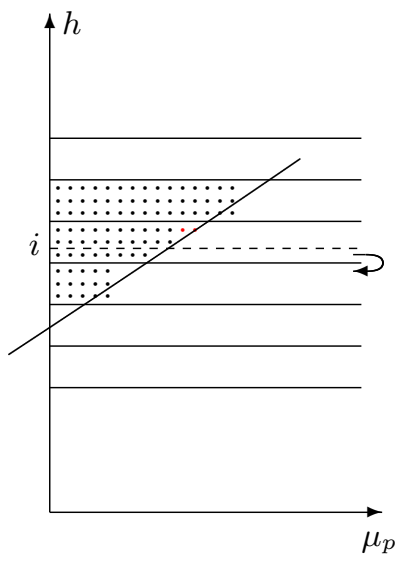

Fig. 6. Below a local maximum, linear approximations reduce the amount of transported particles. The red circles indicate particles which do not sediment in the trapezoid scheme but would sediment in the simple upwind scheme.

within one time step. (Please note: in contrast to the simple upwind scheme which works with height coordinates (in m), the first order scheme is formulated for pressure units.) As pointed out above, there are two possibilities for choosing the two points which define the straight line approximation. In addition to the box of interest $(i)$ the grid box above $(i-1)$ or the box below $(i+1)$ can be chosen. There is no optimal choice in general, as each variant of the straight line approximations has advantages for some profiles and disadvantages for others. The one selected for the MESSy submodel SEDI has performed well in a series of tests within the submodels PSC (for more details see Buchholz, 2005). It is characterised by a rather straightforward implementation as explained in the following:

Approximation above a local maximum:

If the grid box $i$, from which sedimentation is to be calculated, is located above a peak, the straight line is drawn through the mixing ratio values in the grid boxes $i$ and $i+1$ (see Fig. 5). This leads to increased sedimentation compared to the simple upwind scheme.

For steep $\mu_{p}$ gradients above a local maximum, the above equations can lead to trapezoid areas larger than the product $\mu_{p}(i) \times\left(p_{\text {bot }}(i)-p_{\text {top }}(i)\right)$. If these large trapezoid values are used in the sedimentation calculation, more particle substance than currently present in grid box $i$ would be moved into grid box $i+1$. To avoid this unphysical behaviour, the transported substance is limited to the total available amount.

Approximation below a local maximum:

For grid boxes below a peak in the $\mu_{p}$ profile, the routine calculates the two alternative straight line approximations. The sedimentation is then calculated using the smaller trapezoid. Compared to the simple upwind scheme, sedimentation below a local maximum is reduced (see Fig. 6).
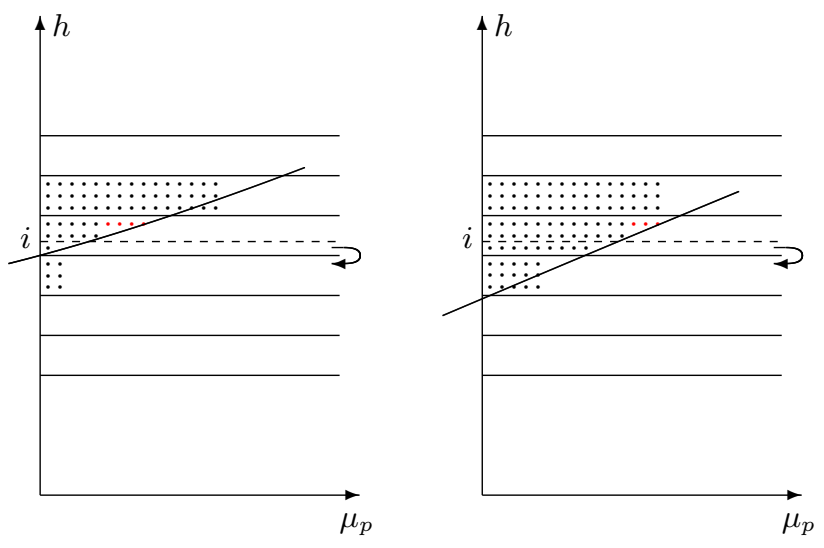

Fig. 7. The linear approximation below a local maximum is based on the mixing ratio $\mu_{p}$ from grid box $i$ and $i-1$ above if $\mu_{p}(i)$ is relatively small compared to $\mu_{p}(i-1)$ (see left figure). If $\mu_{p}(i)$ is only slightly smaller than $\mu_{p}(i-1)$, the linear approximation is based on the $\mu_{p}$ values in grid boxes $i$ and $i+1$ (see right figure). The criterion is which approximation yields the smaller trapezoid.

The above choice leads to the use of $\mu_{p}$ values from the grid box $i$ and $i-1$, if $\mu_{p}(i)$ is relatively small compared to $\mu_{p}(i-1)$ (see left hand side of Fig. 7). These cases are interpreted as a local maximum in the vertical $\mu_{p}$ profile which is mainly in grid box $i-1$, but extends slightly into grid box $i$. Thus it seems appropriate to approximate $\mu_{p}(i-1)$ in such a way that most particles are located in the upper part of grid box $i$. For steep $\mu_{p}$ gradients, however, the above equations can lead to negative trapezoid areas. In those cases, no particle sedimentation takes place.

For $\mu_{p}(i)$ values only slightly below $\mu_{p}(i-1)$, the vertical $\mu_{p}$ profile is interpreted as a peak which has fully arrived in grid box $i$ and extends into grid box $i+1$. The vertical $\mu_{p}$ profile near the $i$ to $(i+1)$ interface is thus best approximated by means of $\mu_{p}(i)$ and $\mu_{p}(i+1)$ (see Fig. 7).

Treatment of local extrema:

For local extrema in the vertical $\mu_{p}$ profile, the influence of nearby grid boxes on the particle distribution inside grid box $i$ is less evident. Therefore, if the grid box $i$ under consideration is a local maximum or a local minimum, the vertical $\mu_{p}$ profile is not approximated by straight lines. Hence the area which defines the amount of sedimenting substance is not a trapezoid but a rectangle corresponding to the product $\mu_{p}(i) \Delta p_{\text {sed }}(i-1)$, similar to the simple upwind scheme.

Finally, it is important to note that both schemes are not monotonic as it is necessary for sedimentation schemes, as a particle mixture can disperse, because larger particles fall faster than smaller ones. This characteristic in particular rules out the application of advection algorithms for simulating the process of sedimentation, since advection requires monotonicity (Buchholz, 2005). 


\subsection{Integration of the submodels into the MESSy system}

The key component to automatise the calculation for all tracers is the functionality provided by the generic MESSy submodel TRACER. The properties of the tracers including the switches which processes should be applied to the tracers are all stored within the meta-information structure provided by the submodel TRACER and are defined during the definition of a tracer (see Jöckel et al., 2006 ${ }^{1}$ ).

\subsubsection{Gas phase dry deposition}

The important information held by the tracer metainformation structure required for the gas phase tracer dry deposition are:

- medium: The medium of the tracer must be AIR.

- ndrydep: This switch must be set to ON indicating that a tracer should be subject to dry deposition.

- molarmass and henry: With the exception of $\mathrm{H}_{2} \mathrm{SO}_{4}$ the molar mass and the effective Henry's Law coefficient (in $\mathrm{mol} /\left(\mathrm{dm}^{3} \mathrm{~atm}\right)$ ) must be declared for the tracer in order to activate the dry deposition calculation. The effective Henry's Law coefficient is defined for water with near-neutral pH (Wesely, 1989).

- dryreac_sf: This is the factor especially defined for dry deposition calculations. dryreac_sf is the factor $s_{\text {reac }}$ (see Sect. 2.1.1 and Appendix A2). It scales the reactivity of a respective tracer to the reactivities of ozone and sulfur dioxide.

If a tracer fulfils all these requirements the dry deposition velocity for this tracer is calculated according to the formulas given in Sect. 2.1.1 and in Appendix A.

To take into account that the mixing ratio used to calculate the dry deposition flux continuously decreases during the time step due to dry deposition and to avoid total depletion in one grid box for very efficiently depositing species (e.g.

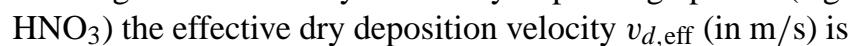
calculated from the dry deposition velocity $v_{d}$ (calculated as described in Sect. 2.1), according to

$v_{d, \mathrm{eff}}=\frac{\Delta z}{\Delta t} \times\left[1-\exp \left(-v_{d} \frac{\Delta t}{\Delta z}\right)\right]$

with $\Delta t$ time step in s and $\Delta z$ layer thickness in $\mathrm{m}$.

From this effective dry deposition velocity and the current tracer mixing ratio $\mu$ (in $\mathrm{mol} / \mathrm{mol}$ ) the dry deposition flux $F_{\text {ddep }}\left(\right.$ in $\left.\frac{\mathrm{mol}}{\mathrm{mol}} \frac{\mathrm{kg}}{\left(\mathrm{m}^{2} \mathrm{~s}\right)}\right)$ is calculated by

$F_{\text {ddep }}=\mu \times \frac{\Delta p}{g \Delta z} \times v_{d, \text { eff }}$

DRYDEP provides two possibilities to assign the dry deposition flux to the tracer:

\footnotetext{
${ }^{1}$ Jöckel, P., in preparation, 2006.
}

- The flux is directly provided as the lower boundary condition for the vertical diffusive flux.

- A tracer tendency $(\Delta \mu / \Delta t$ in $\mathrm{mol} /(\mathrm{mol} \mathrm{s}))$ is calculated from the flux:

$$
\frac{\Delta \mu}{\Delta t}=F_{\text {ddep }} \times \frac{\Delta p}{g}
$$

This tendency is then applied to the tracer within the time integration scheme of the base model.

In the diagnostic output, the dry deposition flux $F_{\text {ddep,diag }}$ in the more common units of $1 /\left(\mathrm{m}^{2} \mathrm{~s}\right)$ is given, calculated by

$F_{\text {ddep }, \text { diag }}=F_{\text {ddep }} \times \frac{N_{A}}{10^{-3} M_{\text {air }}}$

with $N_{A}$ Avogadro constant $\left(6.022 \times 10^{23} 1 / \mathrm{mol}\right)$ and $M_{\text {air }}$ the molar mass of dry air in $\mathrm{g} / \mathrm{mol}$.

\subsubsection{Aerosol dry deposition and sedimentation}

The processing of aerosol tracers subject to dry deposition and/or sedimentation is very similar. Both submodels take advantage of the TRACER meta-information structure. During the initialisation phase of the submodels all tracers are tested if their flags ndrydep or nsedi for dry deposition or sedimentation, respectively are switched $\mathrm{ON}$, and if the medium of the tracer is AEROSOL. In this case the name of the aerosol model (with which the tracer is associated) is memorised $^{2}$. Thereafter, it is checked whether the required aerosol models are running. For all tracers which are associated with an aerosol model that is not switched on, no dry removal (neither dry deposition, nor sedimentation) is calculated. This is because the dry removal of an aerosol particle depends on its properties, i.e. on the radius $r_{p}$ (in $\mathrm{m}$ ), the aerosol density $\rho_{p}$ (in $\left.\mathrm{kg} / \mathrm{m}^{3}\right)$ and - for modal distributions - on the radius standard deviation $\sigma_{p}$ (see Appendix B and Sect. 2.2.1 for DRYDEP and SEDI, respectively.) These three input fields for each aerosol model are obtained via the MESSy data transfer/export interface. This also includes the information about the number of modes and/or bins treated in the respective aerosol model.

The terminal velocities are calculated for each mode/bin of each aerosol model. After those calculations are finished for all aerosol models, each tracer is checked for its medium and the flags ndrydep or nsedi. For the flux calculation of the individual tracer, the terminal velocity of the mode/bin of the corresponding aerosol model is used.

\footnotetext{
${ }^{2}$ The automatic detection of the required aerosol models by inquiring the TRACER meta-information structure is not part of the versions of the DRYDEP and SEDI code included in version 1.1 of MESSy, but will be provided with future releases. In version 1.1 instead, a list of all aerosol models implemented in MESSy is coded.
} 
In addition to the three dimensional application, simple box models exist which calculate in dependence on the aerosol radius, the aerosol density and the standard deviation the aerosol dry deposition or aerosol sedimentation velocities, respectively. As the numerical representation of the sedimentation process is operating within a column, an additional 1-dimensional (1D) model for SEDI is available. Results of these box and column models are shown in Sect. 3.2 and Sect. 3.3, respectively.

\subsubsection{Coupling to the AIRSEA submodel}

The MESSy submodel AIRSEA (Pozzer et al., 2006) determines the exchange of distinct tracers at the ocean surface. These exchanges are net fluxes of emission and dry deposition. Thus it is desirable to switch off the dry deposition calculation of the respective tracer in grid boxes over the ocean, to avoid "double counting" of this removal process. DRYDEP automatically tests if the submodel AIRSEA is switched on, and which tracers are affected. For those tracers whose ocean/atmosphere exchange is calculated directly by AIRSEA, the calculated dry deposition velocity within DRYDEP is set to zero for grid boxes with a land fraction smaller than 0.5:

$v_{d}=\left\{\begin{array}{rll}v_{d} & \text { for } & f_{\text {land }} \geq 0.5 \\ 0 & \text { for } & f_{\text {land }}<0.5\end{array}\right.$.

\section{Examples}

\subsection{Gas phase dry deposition}

As ozone and sulfur dioxide are the two trace gases to which the other gases are scaled, Figs. 8 and 9 depict the annually averaged dry deposition velocities of ozone and sulfur dioxide, respectively. Ozone reaches the highest deposition velocities over land due to the dense vegetation cover in summer associated with an efficient uptake by the stomata, whereas $\mathrm{SO}_{2}$ shows its deposition maxima over the oceans, due to its higher solubility.

Figure 10 shows the annually averaged dry deposition velocity of peroxy acetyl nitrate (PAN). PAN is associated with a reactivity coefficient of $s_{\text {reac }}=0.1$, i.e. the reactivity of PAN is between those of ozone and sulfur dioxide. The same holds for the solubility. According to its effective Henry's Law coefficient PAN is more soluble than ozone, but less soluble than $\mathrm{SO}_{2}$ (see Table 1 for the assumed reactivity coefficients and the effective Henry's Law coefficients).

The scaling of the deposition velocity of PAN between those of the two trace gases ozone and $\mathrm{SO}_{2}$ becomes obvious in the desert regions and over the oceans. In the desert regions the deposition velocities of PAN are smaller than those of ozone showing minima similar to the $\mathrm{SO}_{2}$ deposition velocities in these regions. Over the ocean the dry deposition velocities are smaller for PAN compared to ozone. As the

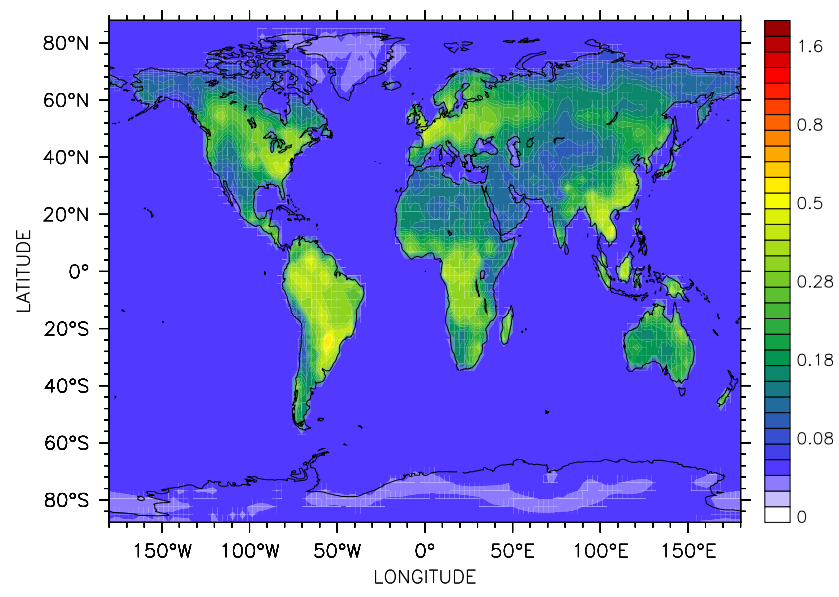

Fig. 8. Annually averaged dry deposition velocity of ozone $(\mathrm{cm} / \mathrm{s})$.

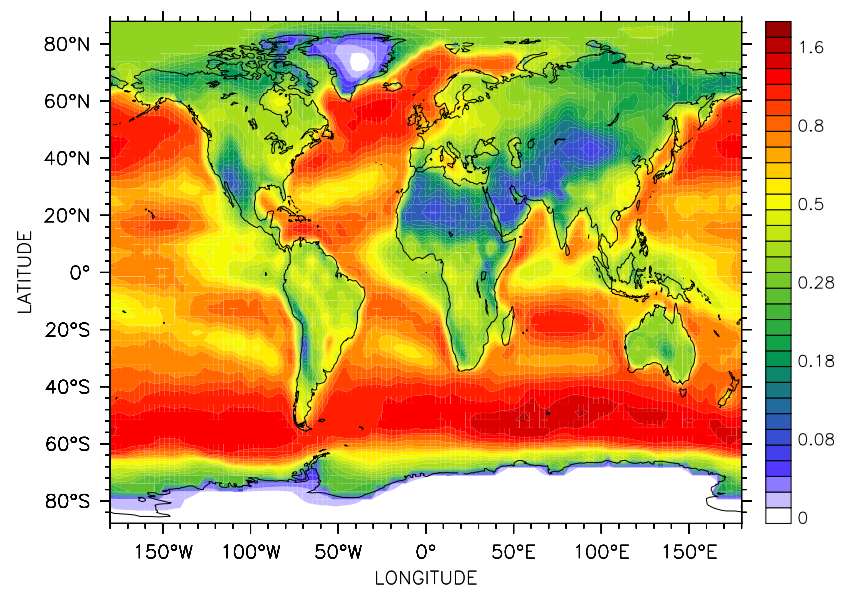

Fig. 9. Annually averaged dry deposition velocity of $\mathrm{SO}_{2}(\mathrm{~cm} / \mathrm{s})$.

effective Henry's Law coefficient of PAN is smaller than that of $\mathrm{SO}_{2}$ and the reactivity coefficient for PAN is smaller than for ozone, the sea-surface uptake resistance is larger resulting in a smaller dry deposition velocity compared to ozone (see Eq. (A15), Appendix A2).

Formic acid (HCOOH, see Fig. 11) is a second example for a species which dry deposition velocity is calculated by scaling to $\mathrm{SO}_{2}$ and ozone. The reactivity coefficient is 0 , as for $\mathrm{SO}_{2}$, but the solubility of $\mathrm{HCOOH}$ is higher than the solubility of the two other trace gases. This causes higher dry deposition velocities as compared to $\mathrm{SO}_{2}$ and ozone.

\subsection{Aerosol dry removal: box model examples}

The following two examples are calculated in simple box models prescribing standard pressure (101325 Pa) and a temperature of $298.15 \mathrm{~K}$ as environmental conditions. 


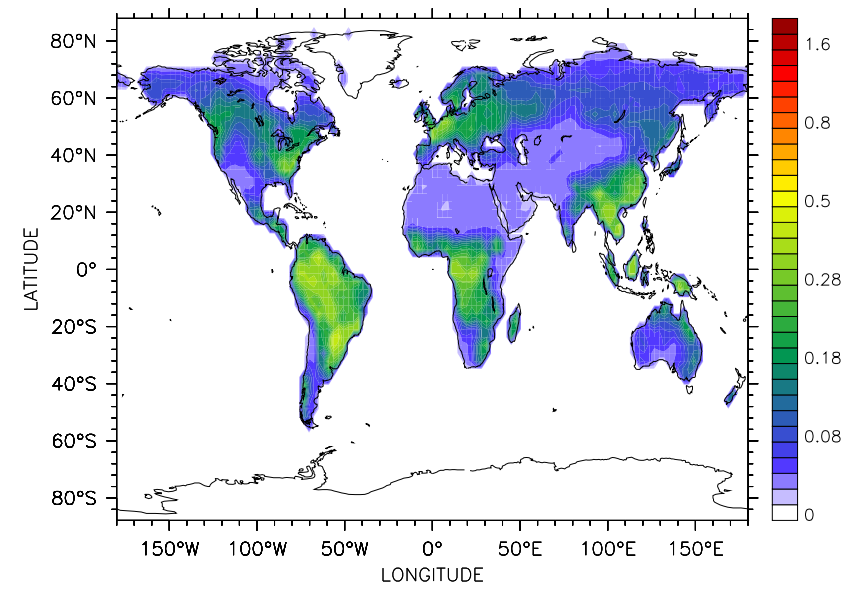

Fig. 10. Annually averaged dry deposition velocity of PAN $(\mathrm{cm} / \mathrm{s})$ as example of a relatively unsoluble, but reactive species.

Table 1. Assumed dimensionless reactivity coefficient $\left(s_{\text {reac }}\right)$ and effective Henry's Law coefficients (in $\mathrm{mol} /\left(\mathrm{dm}^{3} \mathrm{~atm}\right)$ ) for the four gas phase species shown in the examples. The effective Henry's Law coefficients are for water with near-neutral $\mathrm{pH}$. As the resistances for $\mathrm{O}_{3}$ and $\mathrm{SO}_{2}$ are pre-described according to Ganzeveld and Lelieveld (1995) and Ganzeveld et al. (1998), i.e., following Wesely (1989), their Henry's Law coefficients are the same as in Wesely (1989).

\begin{tabular}{ccccc}
\hline Species $\mathrm{X}$ & $\mathrm{O}_{3}$ & $\mathrm{SO}_{2}$ & $\mathrm{HCOOH}$ & $\mathrm{PAN}$ \\
\hline$S_{\text {reac }}(X)$ & 1 & 0 & 0 & 0.1 \\
$H(X)$ & 0.01 & $1 \times 10^{5}$ & $4 \times 10^{6}$ & 3.6 \\
\hline
\end{tabular}

\subsubsection{Aerosol sedimentation velocities}

Figure 12 illustrates the dependency of the sedimentation velocity of aerosol particles on the aerosol density and on the particle radius. The curves are shown for radii of $20 \mathrm{~nm}$, $40 \mathrm{~nm}, 80 \mathrm{~nm}, 160 \mathrm{~nm}, 320 \mathrm{~nm}$ and $640 \mathrm{~nm}$, respectively. The sedimentation velocity increases with increasing density and increasing radius.

\subsubsection{Aerosol dry deposition velocities}

In Fig. 13 the aerosol dry deposition velocity (in $\mathrm{m} / \mathrm{s}$ ) is shown versus the aerosol radius calculated for land surfaces and for three different aerosol densities. To give a range of realistic dry deposition velocities, the densities of $500 \mathrm{~kg} / \mathrm{m}^{3}$, $1500 \mathrm{~kg} / \mathrm{m}^{3}$ and $3000 \mathrm{~kg} / \mathrm{m}^{3}$ are chosen to cover the usual aerosol density range.

The aerosol dry deposition velocity as function of the aerosol radius shows a minimum around $0.5 \mu \mathrm{m}$. The influence of the aerosol density is negligible for aerosol radii below approximately $1 \mu \mathrm{m}$. For particles larger than $1 \mu \mathrm{m}$ the dry deposition velocities are the higher the denser the particle is.

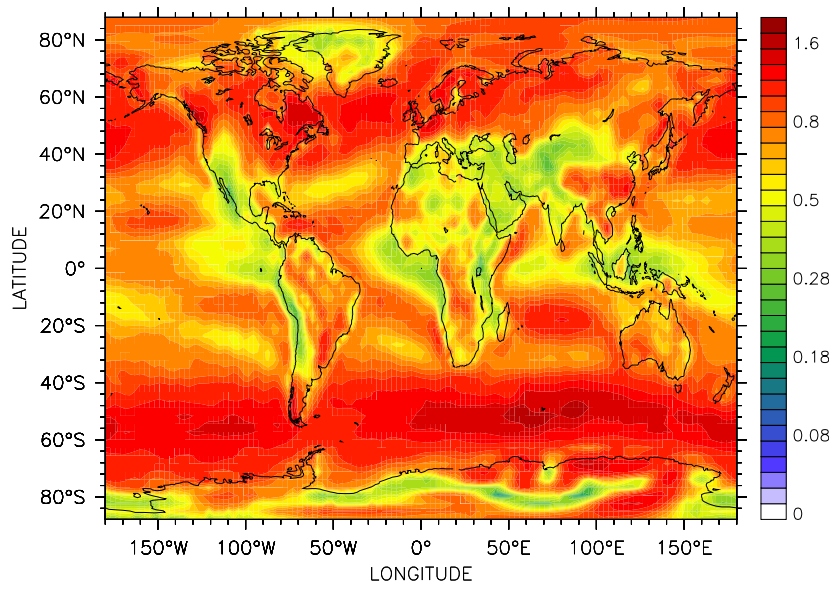

Fig. 11. Annually averaged dry deposition velocity of $\mathrm{HCOOH}$ $(\mathrm{cm} / \mathrm{s})$ as example of a soluble less reactive species.

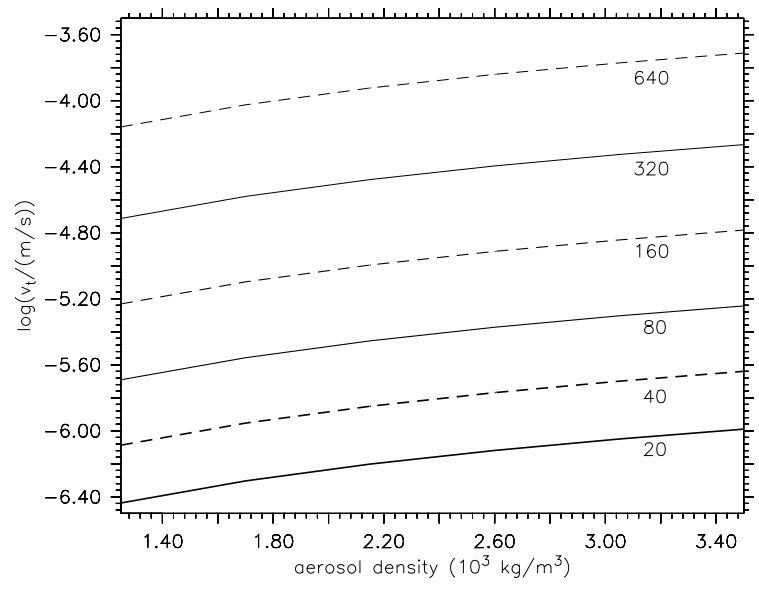

Fig. 12. Logarithm of the aerosol sedimentation velocities (in $\mathrm{m} / \mathrm{s}$ ) dependent on aerosol density (in $\mathrm{kg} / \mathrm{m}^{3}$ ). The velocities increase with increasing density and radius. The corresponding radii from bottom to top are $20 \mathrm{~nm}, 40 \mathrm{~nm}, 80 \mathrm{~nm}, 160 \mathrm{~nm}, 320 \mathrm{~nm}$ and $640 \mathrm{~nm}$.

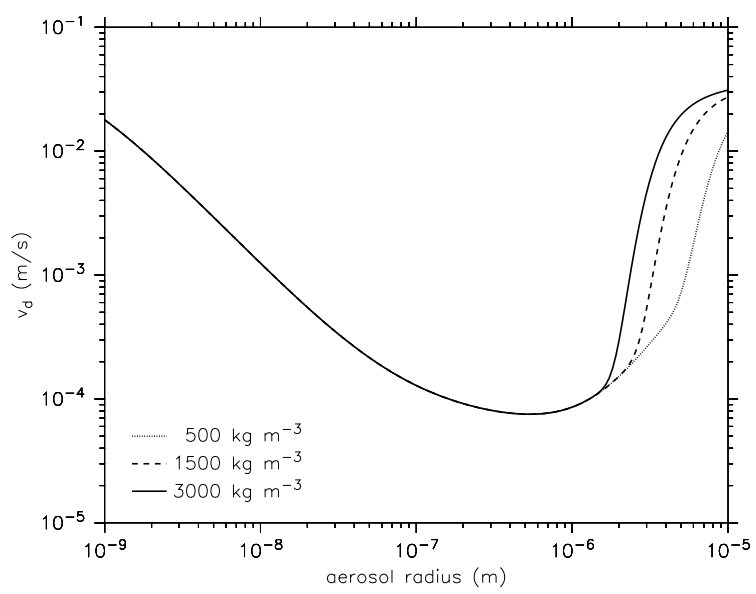

Fig. 13. Aerosol dry deposition velocity (in $\mathrm{m} / \mathrm{s}$ ) dependent on the aerosol radius for three different aerosol densities. 

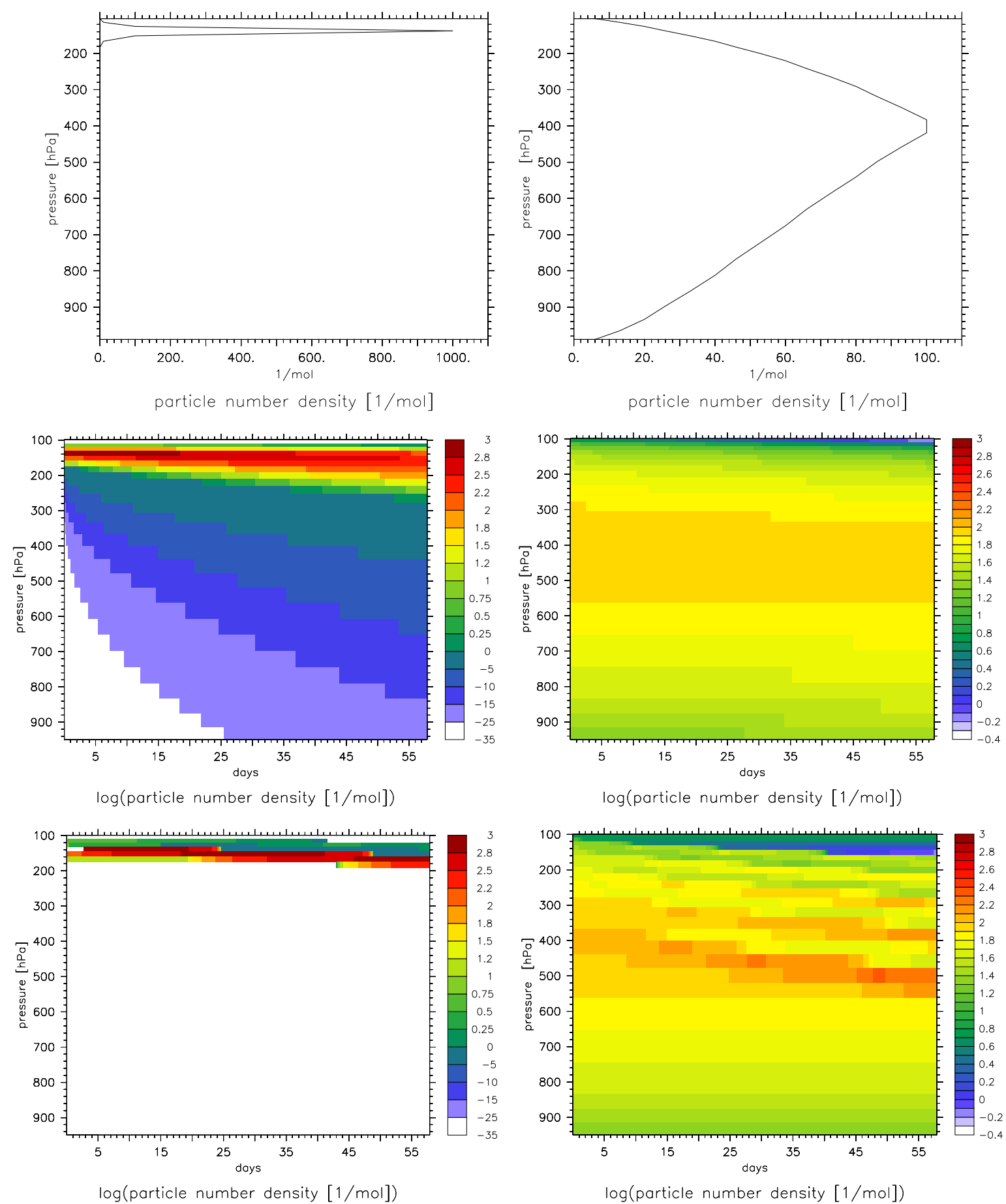

Fig. 14. SEDI column model example. The upper panels display the initial vertical distributions of the number density (1/mol). The panels in the middle row show the evolution of the vertical distribution calculated with the simple upwind scheme and the results for the first order sedimentation scheme are depicted in the lower row. For a better visualisation of the particle distribution, the logarithm of the number density is shaded with an irregularly spaced colour bar. Left: example 1; Right: example 2.

\subsection{Aerosol sedimentation: column model examples}

In the following results of the SEDI column model are shown. Using two different initial conditions the advantages and disadvantages of the sedimentation schemes of zeroth or- der and of first order are shown. For all examples a constant aerosol density of $1000 \mathrm{~kg} / \mathrm{m}^{3}$ and a constant aerosol radius of $1 \mu \mathrm{m}$ have been chosen. The example simulations have been performed with a timestep of $1000 \mathrm{~s}$. 


\subsubsection{Column example 1}

As a first example a sharp peak of up to $10001 / \mathrm{mol}$ in the initial tracer number density spread between 100 and $180 \mathrm{hPa}$ (see Fig. 14, upper left) is chosen. The left panel in the middle row of Fig. 14 shows the resulting evolution of the vertical distribution of the number density calculated with the simple upwind sedimentation scheme.

The initially sharp peak broadens over time; a few particles reach the surface within 25 days. In contrast to this, the first order sedimentation scheme (Fig. 14, lower left) preserves the shape of the initial distribution while the maximum slowly moves downward.

\subsubsection{Column example 2}

In the second example a wider particle distribution is initialised (Fig. 14, upper right). The maximum is by a factor of 10 lower than in example 1 and located further down around $400 \mathrm{hPa}$. With the simple upwind scheme the overall vertical distribution does not change much with time (Fig. 14, middle right). Nevertheless, the uppermost layers are nearly depleted of particles at the end of the simulation.

For the first order sedimentation scheme it becomes apparent that it is - as the process in reality - not monotonic (Fig. 14, lower right). Therefore, new local maxima develop over time in addition to the initial peak which is preserved in shape and slowly moves downward.

\section{Summary}

We have presented the new MESSy submodels DRYDEP and SEDI for dry deposition of gas and aerosol tracers and sedimentation of aerosol particles, respectively. As part of the community model MESSy they are available to our colleagues in atmospheric chemistry and climate research upon request. See http://www.messy-interface.org for details.

\section{Appendix A Calculation of resistances}

\section{A1 Aerodynamic resistances}

The aerodynamic resistances strongly vary depending on the three surface types land, water and ice/snow. The aerodynamic resistance over land is split into a bare soil and snow (slsn) and a vegetation (veg) part. Thus, in Eq. (3) the index $t$ indicates the surface type, i.e., $t$ is one of veg (vegetation), slsn (bare soil/snow), ice (sea ice/sea snow) and wat (water).

Some special assumptions are made for the roughness length $z_{0, m}$ (in $\mathrm{m}$ ). It is set to $0.005 \mathrm{~m}$ for the surface type slsn and for the surface type veg it is set to a minimum of

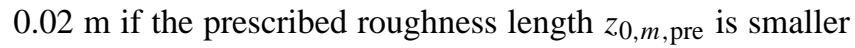

than $0.02^{3}$. For all other surface types the unchanged $z_{0, m \text {,pre }}$ is used. The prescribed roughness length and the prescribed Leaf Area Index (LAI, used for the calculation of the surface resistance over vegetation in Eq. A7) have been preprocessed using land cover data (Olson, 1992) and additional NDVI (Normalised Difference Vegetation Index) data. For more information see Ganzeveld et al. (2002) and Ganzeveld et al. (2006).

The friction velocity $u_{\star, t}(\mathrm{~m} / \mathrm{s})$ depends on the surface type $t$ :

$u_{\star, t}=\sqrt{c_{m, t}} \times\left|v_{h}\right|$

where $\left|v_{h}\right|=\sqrt{\left(u^{2}+v^{2}\right)}$ is the horizontal wind speed (in $\mathrm{m} / \mathrm{s}$ ), and the dimensionless, surface type dependent drag coefficient $c_{m, t}$ is the product of the neutral drag coefficient $c_{n d, t}$, the momentum drag $(m d)$ coefficient $c_{m d, t}$ and the exchange parameter $c_{e x, t}$ (all dimensionless and provided by the base model):

$c_{m, t}=\frac{c_{n d, t} \times c_{m d, t}}{c_{e x, t}}$

Note, that all these coefficients depend on the surface type.

The stability function $\Phi_{h, t}$ not only depends on the surface type, but also on the Richardson number $(R i)$, which is provided by the base model, (see e.g. Stull, 1988, pp.383):

- $R i>0$, i.e. stable conditions:

In this case the stability function depends on the MoninObukhov-Length $L(\mathrm{~m})$, and on the layer thickness $\Delta z$ in $\mathrm{m}$.

$\Phi_{h, t}=4.7 \times \frac{\Delta z}{L}$

- $R i \leq 0$, i.e. neutral and unstable conditions: The stability function $\Phi_{h, t}$ depends on the profile functions at the surface $\Psi_{h}$. This is constant for neutral conditions

$\Psi_{h, \text { neut }}=0.74$

and depends on the Richardson number for unstable conditions

$$
\Psi_{h, t, u s}=0.74 \times \sqrt{1-9 R i_{t}} .
$$

\footnotetext{
${ }^{3}$ Note: These assumptions are appropriate, as the external input field of surface roughness is in $0.5^{\circ} \times 0.5^{\circ}$ resolution. During the model initialisation phase this high resolution information is rediscretised (Jöckel, 2006) for the usually coarser model resolution. The resulting average within a model grid box is potentially too large for the bare soil and snow fraction of the box. Consequently the assumption of a constant surface roughness of $0.005 \mathrm{~m}$ for $s l s n$ yields more realistic results. For overgrown surfaces the opposite is the case. In a model grid box with a high fraction of bare soil and snow, the average value for the roughness length is potentially too small for the vegetation covered fraction. As the roughness length of vegetation is normally larger than $0.02 \mathrm{~m}$ a minimum of $0.02 \mathrm{~m}$ is appropriate.
} 
Table A1. Predefined gas phase tracer resistances (in $\mathrm{s} / \mathrm{m}$ ) in DRYDEP: $\mathrm{R}_{\text {mes }}$ is the mesophyll resistance, $\mathrm{R}_{\text {cut }}$ the cuticular resistance, $\mathrm{R}_{s \text {,soil }}, \mathrm{R}_{s, \text { snow }}, \mathrm{R}_{s, \text { ws }}$ and $\mathrm{R}_{s, \text { wat }}$ are the surface resistances for bare soil, snow/ice, wet skin and water, respectively. A, $\mathrm{B}$ and $\mathrm{C}$ indicate special cases as listed in Appendix A2.1.

\begin{tabular}{lllllll}
\hline Species & $\mathrm{R}_{\text {mes }}$ & $\mathrm{R}_{\text {cut }}$ & $\mathrm{R}_{s, \text { soil }}$ & $\mathrm{R}_{s, \text { snow }}$ & $\mathrm{R}_{s, \text { ws }}$ & $\mathrm{R}_{s, \text { wat }}$ \\
\hline $\mathrm{SO}_{2}$ & 1 & $10^{5}$ & $\mathrm{C}$ & $\mathrm{B}$ & 100 & 1 \\
$\mathrm{O}_{3}$ & 1 & $10^{5}$ & 400 & 2000 & 2000 & 2000 \\
$\mathrm{HNO}_{3}$ & 1 & 1 & 1 & $\mathrm{~B}$ & 1 & 1 \\
$\mathrm{NO}$ & $\mathrm{A}$ & $10^{5}$ & $10^{5}$ & $10^{5}$ & $10^{5}$ & $10^{5}$ \\
$\mathrm{NO}_{2}$ & $\mathrm{~A}$ & $10^{5}$ & 600 & $10^{5}$ & $10^{5}$ & $10^{5}$ \\
\hline
\end{tabular}

The constant 0.74 is an approximation for the ratio of the diffusivities of heat and momentum (see Stull, 1988, p. 384 for details). The dimensionless stability function $\Phi_{h, t}$ is then given by

$$
\begin{aligned}
\Phi_{h, t}= & {\left[2 \log \left(\frac{1+\Psi_{h, t, u s}}{2}\right)+\log \left(\frac{1+\Psi_{h, t, u s}^{2}}{2}\right)\right.} \\
& \left.-2 \arctan \left(\Psi_{h, t, u s}\right)\right] \\
& -\left[2 \log \left(\frac{1+\Psi_{h, \text { neut }}}{2}\right)+\log \left(\frac{1+\Psi_{h, \text { neut }}^{2}}{2}\right)\right. \\
& \left.-2 \arctan \left(\Psi_{h, \text { neut }}\right)\right] .
\end{aligned}
$$

\section{A2 Surface resistances}

As stated above, the calculation of the surface resistances for most of the trace gases is taken from Wesely (1989). Thus most of the following equations can be found in that paper where also more details are given about the ideas of this parameterisation. The surface resistances depend on the properties of the individual trace gas $X$. They are calculated according to Wesely (1989), except of the trace gases listed in Table A1. These specific surface uptake resistances are explicitly calculated according to parameterisations described in more detail below, or are assigned specific values based on an extensive review of available observations (see Ganzeveld and Lelieveld, 1995; Ganzeveld et al., 1998). For most of the trace gases, the surface resistances are estimated from the respective resistances of $\mathrm{SO}_{2}$ and $\mathrm{O}_{3}$. The factor $s_{\text {reac }}(X)$ defines a weight, i.e., whether a species behaves more like $\mathrm{SO}_{2}$ or $\mathrm{O}_{3}$. In addition to $\mathrm{SO}_{2}$ and $\mathrm{O}_{3}$, most surface resistances of $\mathrm{HNO}_{3}$, NO and $\mathrm{NO}_{2}$ are also predefined and not calculated (see Table A1). The exceptions (indicated by a letter in Table A1) are explained in detail at the end of this section.

The surface resistances required for the calculation of the dry deposition velocities in Eqs. (6) and (8) are determined as follows:
- The surface soil resistance $R_{s, \text { soil }}(X)$ :

The parameterisation is given by Eq. (9) in Wesely (1989):

$R_{s, \text { soil }}(X)=\left(\frac{H(X)}{10^{5} \times R_{s, \text { soil }, \mathrm{SO}_{2}}}+\frac{s_{\text {reac }}(X)}{R_{\text {s,soil }, \mathrm{O}_{3}}}\right)^{-1}$,

where $H(X)$ is the Henry's Law coefficient in $\mathrm{mol} /\left(\mathrm{dm}^{3} \mathrm{~atm}\right)$ of the respective trace gas X. $R_{s, \text { soil }, \mathrm{SO}_{2}}$ and $R_{s, \text { soil }, \mathrm{O}_{3}}$ are the soil surface resistances of $\mathrm{SO}_{2}$ and $\mathrm{O}_{3}$, respectively.

- Surface vegetation resistance $R_{s, v e g}(X)$ :

$$
\begin{aligned}
R_{s, v e g}(X)= & {\left[\left(R_{\text {can }}+R_{q b r, v e g}(X)\right.\right.} \\
& \left.\left.+R_{s, \text { soil }}(X)\right)^{-1}+\left(\frac{\mathrm{LAI}}{R_{\text {leaf }}(X)}\right)\right]^{-1}
\end{aligned}
$$

$R_{s, \text { soil }}$ is the soil surface resistance as defined in the previous item and $R_{q b r, v e g}$ is the quasi-laminar boundary layer resistance for vegetation, as described by Eq. (4). $L A I$ is the prescribed leaf area index in $\mathrm{m}^{2} / \mathrm{m}^{2}$. The canopy resistance $R_{\text {can }}$ is calculated by

$R_{\mathrm{can}}=14 \times \frac{h_{\mathrm{can}}}{u_{\star, v e g}}$,

where $h_{\text {can }}$ is the canopy height $(\mathrm{m})$ and $u_{\star, v e g}$ the friction velocity for vegetation $(\mathrm{m} / \mathrm{s})$. The leaf resistance $R_{\text {leaf }}$ depends on the cuticular resistance $R_{\text {cut }}$, the mesophyll resistance $R_{\text {mes }}$ and on the stomatal resistance corrected for differences between water and the respective species $X, R_{\text {stom, corr }}(X)$ :

$$
\begin{aligned}
& R_{\text {leaf }}(X)= \\
& \left(\frac{1}{R_{\text {cut }}(X)}+\frac{1}{R_{\text {stom, corr }}(X)+R_{\text {mes }}(X)}\right)^{-1} .
\end{aligned}
$$

The three resistances are determined by

- Mesophyll resistance $R_{\text {mes }}(X)$ :

$$
R_{\text {mes }}(X)=\left(\frac{H(X)}{3000}+100 \times s_{\text {reac }}(X)\right)^{-1},
$$

as given by Eq. (6) in Wesely (1989).

- Cuticular resistance $R_{\text {cut }}(X)$ :

$$
R_{\text {cut }}(X)=\frac{R_{\text {cut }, \mathrm{O}_{3}}}{10^{-5} \times H(X)+s_{\text {reac }}(X)},
$$

see Eq. (7) in Wesely (1989). 
- Corrected stomatal resistance $R_{\text {stom,corr }}(X)$ :

The calculation of this term is based on Eq. (4) of Wesely (1989):

$R_{\text {stom, corr }}(X)=\frac{M(X)}{M_{\mathrm{H}_{2} \mathrm{O}}} \times \frac{R_{\text {stom }}}{\Psi_{\text {sm }}}$.

Here, $M(X)$ and $M_{\mathrm{H}_{2} \mathrm{O}}$ are the molar masses of the species $X$ and water, respectively $(\mathrm{g} / \mathrm{mol}) . R_{\text {stom }}$ is the leaf stomatal resistance $(\mathrm{s} / \mathrm{m})$ and $\Psi_{s m}$ the soil moisture stress function. Both are provided by the base model.

- Surface snow resistance $R_{s, \text { snow }}(X)$ :

$$
\begin{aligned}
& R_{S, \text { snow }}(X)= \\
& \left(\frac{H(X)}{10^{5} \times R_{s, \text { snow }, \mathrm{SO}_{2}}}+\frac{s_{\text {reac }}(X)}{R_{S, \text { snow }, \mathrm{O}_{3}}}\right)^{-1}
\end{aligned}
$$

This formula is given by Eq. (8) in Wesely (1989).

- Wet skin resistance $R_{s, w s}(X)$ :

The solubility of the trace gas is of special importance in the wet skin fraction (see Wesely (1989), Eq. 14):

$$
\begin{aligned}
& R_{S, w s}(X)= \\
& \left(\frac{1 / 3}{R_{S, w s, \mathrm{SO}_{2}}}+10^{-7} \times H(X)+\frac{s_{\text {reac }}(X)}{R_{s, w s, \mathrm{O}_{3}}}\right)^{-1}
\end{aligned}
$$

- Sea-surface uptake resistance $R_{s, w a t}(X)$ :

$$
\begin{aligned}
R_{S, \text { wat }} & (X)= \\
& \left(\frac{H(X)}{10^{5} \times R_{S, \text { wat }, \mathrm{SO}_{2}}}+\frac{s_{\text {reac }}(X)}{R_{S, \text { wat }, \mathrm{O}_{3}}}\right)^{-1}
\end{aligned}
$$

\section{A2.1 Special cases}

Table A1 lists the predefined resistances used to calculate the surface resistances. There are three exceptions indicated by the letters $\mathrm{A}, \mathrm{B}$ and $\mathrm{C}$ within the table.

A: The mesophyll resistances of $\mathrm{NO}$ and $\mathrm{NO}_{2}$ are calculated from the corrected stomatal resistance of ozone:

$$
\begin{aligned}
& R_{\text {mes }}(\mathrm{NO})=5 \times \mathrm{R}_{\text {stom, corr, } \mathrm{O}_{3}} \\
& R_{\text {mes }}\left(\mathrm{NO}_{2}\right)=0.5 \times \mathrm{R}_{\text {stom, corr, } \mathrm{O}_{3}}
\end{aligned}
$$

B: For $\mathrm{SO}_{2}$ and $\mathrm{HNO}_{3}$ the surface resistances over snow are mainly determined by the surface temperature $T_{s}$ :

$$
\begin{aligned}
R_{S, \text { snow }}\left(\mathrm{SO}_{2}\right) & =R_{S, \text { snow }}\left(\mathrm{HNO}_{3}\right) \\
& =10^{\left(-0.09 *\left(T_{s}-273 .\right)+2.4\right)} .
\end{aligned}
$$

The resistances are further limited to a maximum and minimum value:

$$
10 \leq R_{s, \text { snow }}\left(\mathrm{SO}_{2}\right)=\mathrm{R}_{\mathrm{s}, \text { snow }}\left(\mathrm{HNO}_{3}\right) \leq 10^{5}
$$

Table A2. $\mathrm{pH}$ classes according to Batjes, 1995 and the respective soil resistances (in $\mathrm{s} / \mathrm{m}$ ) for $\mathrm{SO}_{2}$.

\begin{tabular}{lll}
\hline $\mathrm{pH}$ class $j$ & $\mathrm{pH}$ range & $R_{\text {s,soil }}\left(\mathrm{SO}_{2}\right)$ \\
\hline 1 & $\mathrm{pH} \leq 5.5$ & 115 \\
2 & $5.5<\mathrm{pH} \leq 7.3$ & 65 \\
3 & $7.3<\mathrm{pH} \leq 8.5$ & 25 \\
4 & $8.5<\mathrm{pH}$ & 25 \\
5 & $4<\mathrm{pH} \leq 8.5$ & 70 \\
\hline
\end{tabular}

$\mathrm{C}$ : The soil resistance of $\mathrm{SO}_{2}$ is soil $\mathrm{pH}$ dependent. For the calculation of $R_{s, \text { soil }}\left(\mathrm{SO}_{2}\right) 5$ soil $\mathrm{pH}$ classes $j$ (as given by Batjes, 1995) are distinguished. Each of these classes is associated with a prescribed soil resistance $R_{s, s o i l}(j)$. Table A2 lists the different $\mathrm{pH}$ classes and the respective soil resistances. The final soil resistance for $\mathrm{SO}_{2}$ is given by

$$
\begin{aligned}
R_{s, \text { soil }}\left(\mathrm{SO}_{2}\right)= & 1000 \times \exp \left(269-T_{S}\right) \\
& +\sum_{j} f_{j} \times R_{\text {soil }, j} .
\end{aligned}
$$

The $f_{j}$ denote the grid box fractions with soil $\mathrm{pH}$ class $j$.

The soil resistance is further modified for arid regions (relative humidity in $2 \mathrm{~m}$ above surface $\left(r h_{2}\right)$ less than $0.4)$ :

$$
\begin{aligned}
R_{\text {soil,arid }}\left(\mathrm{SO}_{2}\right)= & R_{s, \text { soil }}\left(\mathrm{SO}_{2}\right) * 3.41-85 \\
& \left.+\left(\left(0.4-r h_{2}\right) / 0.4\right) * 10^{5}\right) \\
& +1000 \times \exp \left(269-T_{s}\right)
\end{aligned}
$$

and for semi-arid regions $\left(0.4<r h_{2}<0.6\right)$

$$
\begin{aligned}
& R_{\text {soil,semi-arid }}\left(\mathrm{SO}_{2}\right)= \\
& \quad R_{S, \text { soil }}\left(\mathrm{SO}_{2}\right) * 3.41-85 \\
& +1000 \times \exp \left(269-T_{S}\right) .
\end{aligned}
$$

More details about this approach to account for the soil $\mathrm{pH}$ dependence of the soil resistance are found in Ganzeveld et al. (1998). The required soil pH maps are imported from external input fields. They are in netCDF-format and are provided with the submodel code. 


\section{Appendix B}

\section{Calculation of aerosol dry deposition velocities}

- The particle dry deposition velocity over vegetation $v_{k d, p, v e g}$ is given by

$$
\begin{aligned}
v_{k d, p, v e g}= & \exp \left(-S t_{\text {veg }}^{-0.5}\right) \\
& \times\left(v_{b, v e g}+v_{\text {im,veg }}+v_{\text {in }, \text { veg }}\right)
\end{aligned}
$$

The variables are

- the dimensionless Stokes number over vegetation covered surfaces $S t_{v e g}$ :

$S t_{\text {veg }}=f_{\text {relax }} \frac{100 \times u_{\star, v e g}^{2}}{g \times 0.1}$,

where $u_{\star, v e g}$ is the friction velocity for vegetation in $\mathrm{m} / \mathrm{s}$ as above, $g$ is the gravitational acceleration, and 0.1 is the characteristic radius (in $\mathrm{cm}$ ) for the so-called "largest collector" (= aerosol particle). The relaxation factor $f_{\text {relax }}$ is given by

$f_{\text {relax }}=10^{-3} \frac{\rho_{p}\left(\alpha r_{p}\right)^{2 \beta} \times f_{\text {cun }}}{18 \eta_{d} \kappa}$

with $\rho_{p}$ aerosol density (in $\mathrm{kg} / \mathrm{m}^{3}$ ), $r_{p}$ the particle radius (in $\mathrm{cm}), \eta_{d}$ dynamical viscosity $\left(=1.789 \times 10^{-4} \mathrm{~g} /(\mathrm{cm} \mathrm{s})\right), \kappa=0.4$ von Karman constant and $\alpha$ and $\beta$ given as follows:

$$
\begin{aligned}
\alpha & =1-\left(10.2-23.7 s+14.5 s^{2}\right)(1-0.6) \\
& -\left(-6.7+15.5 s-9.2 s^{2}\right)\left(1-0.6^{2}\right) \\
& +1.2 \exp \left(\frac{0.066 \times s}{\Phi-s}\right) \\
\beta & =\exp \left(\frac{0.00077 \times s}{1.009-s}\right) \\
& \text { with } \Phi=1.058-\frac{0.0155(s-0.97)}{1.02-s^{1.4}}
\end{aligned}
$$

where $s$ is the relative humidity in $2 \mathrm{~m}$ above the surface (in \%). The Cunningham-slip-flow correction factor $f_{\text {cun }}$ is given by

$$
\begin{aligned}
& f_{\text {cun }}= \\
& 1+\frac{\lambda_{p}}{\alpha r_{p}^{\beta}}\left(1.257+0.4 \exp \left(-\frac{1.1 r_{p}}{\lambda_{p}}\right)\right) .
\end{aligned}
$$

$\lambda_{p}=0.066 \times 10^{-4} \mathrm{~cm}$ is the free mean path of a particle. (Note: $\lambda_{p}$ is basically the same as $\lambda_{\text {air }}$ in Eq. (16), but the units in the formulas are different and in SEDI $\lambda_{\text {air }}$ must be calculated for all model layers, whereas $\lambda_{p}$ is only defined in the lowest layer.)
- $v_{b, v e g}$ is the dry deposition velocity due to Brownian diffusion:

$$
v_{b, v e g}=\frac{100 \times u_{\star, v e g}^{2}}{\kappa\left|v_{h}\right|} S c^{\frac{2}{3}}
$$

with $u_{\star, v e g}, \kappa$ and $\left|v_{h}\right|$ given as above. The Schmidt number $S c$ is calculated by

$$
S c=\frac{v}{D_{c}}=0.15 \times\left(\frac{k_{B} T_{s} f_{\text {cun }}}{3 \pi \eta_{d} \alpha r_{p}^{\beta}}\right)^{-1}
$$

$v$ is the kinematic viscosity $\left(0.15 \mathrm{~cm}^{2} / \mathrm{s}\right), k_{B}$ is the Boltzmann constant $\left(1.38 \times 10^{-23}(\mathrm{~J} / \mathrm{K})\right), T_{s}(\mathrm{~K})$ is the surface temperature and $\eta_{d}, \alpha, r_{p}$ and $\beta$ are given as above.

- $v_{\text {im,veg }}$ is determined by the impact of the vegetation surface

$$
v_{\text {im }, v e g}=\frac{100 \times u_{\star, v e g}^{2}}{\kappa\left|v_{h}\right|} \times \frac{S t_{v e g}^{2}}{1+S t_{v e g}^{2}}
$$

- $v_{\text {in,veg }}$ is that part of the deposition including the interception collection efficiency:

$$
v_{\text {in }, \text { veg }}=\frac{100 \times u_{\star, v e g}^{2}}{\kappa\left|v_{h}\right|} \times \frac{1}{2}\left(\frac{r_{p}}{10^{-4}}\right)^{2}
$$

- The particle dry deposition velocity for snow and bare soil $v_{k d, p, s l s n}$ is calculated in a similar way:

$v_{k d, p, s l s n}=v_{b, s l s n}+v_{i m, s l s n}$

with dry deposition due to Brownian diffusion:

$v_{b, s l s n}=\frac{100 \times u_{\star, s l s n}^{2}}{\kappa\left|v_{h}\right|} S c^{\frac{2}{3}}$

and due to impaction

$v_{i m, s l s n}=\frac{100 \times u_{\star, s l s n}^{2}}{\kappa\left|v_{h}\right|} \times 10^{-\frac{3}{S t_{s l s n}}}$,

where $S t_{s l s n}$ is the dimensionless Stokes number for bare soil and snow

$S t_{s l s n}=f_{\text {relax }} \frac{100 \times u_{\star, s l s n}^{2}}{v}$.

- The dry deposition velocity over water $v_{k d, p, w a t}$ is calculated following Hummelshøj et al. (1992) :

$$
\begin{aligned}
& v_{k d, p, w a t}= \\
& \quad(1-\alpha)\left(v_{b, w a t}+v_{\text {im, wat }}\right)+\alpha v_{\text {bubble }}
\end{aligned}
$$

Equation (B16) is equivalent to Eq. (10) in the paper of Hummelsh $\varnothing j$ et al. (1992). $\alpha$ is the relative area of bursting bubbles, approximated by

$\alpha=1.7 \times 10^{-6} \times v_{10, h}^{3.75}$ 
(see Hummelshøj et al. (1992), Eq. 12).

$v_{b, w a t}$ is the dry deposition velocity due to Brownian diffusion, given by

$v_{b, w a t}=\frac{100}{3} \times u_{\star, w a t} \times S c^{-0.5} \times R e^{-0.5}$

with $R e$ Reynolds number and Sc Schmidt number. $v_{i m, w a t}$ is the impaction velocity

$v_{\text {im }, w a t}=100 \times u_{\star, w a t} \times 10^{-\frac{3}{S t_{w a t}}}$

$S t_{\text {wat }}$ is the dimensionless Stokes number for water

$S t_{\text {wat }}=f_{\text {relax }} \frac{100 \times u_{\star, w a t}^{2}}{v}$

and $v_{\text {bubble }}$ describes the influence of bubble bursting and consists of two parts:

$$
\begin{aligned}
v_{\text {bubble }}= & \frac{100 \times u_{\star, w a t}^{2}}{\left|v_{h}\right|} \\
& +E f f \times 2 \pi r_{d}^{2} \times 2 r_{h} \times 500 .
\end{aligned}
$$

The first part describes the atmospheric diffusion velocity, and the second part the wash out velocity. The collection efficiency Eff is assumed to be $0.5,2 \pi r_{d}^{2}$ is the area of a spray drop $\left(r_{d}\right.$ in $\mathrm{m}$ ), and $r_{h}$ is the average height reached by the spray drop (in $m$ ). For more details see Hummelshøj et al. (1992).

Acknowledgements. We thank all MESSy developers and users for their support. The helpful comments of three anonymous referees are gratefully acknowledged. We have used the Ferret program (http://www.ferret.noaa.gov) from NOAA's Pacific Marine Environmental Laboratory for creating some of the graphics in this paper.

Edited by: M. Dameris

\section{References}

Batjes, N. H.: A global data set of soil $\mathrm{pH}$ properties, Tech. Rep. 27, Int. Soil Ref. and Inf. Cent., Wageningen, Netherlands, 1995.

Buchholz, J.: Simulations of Physics and Chemistry of Polar Stratospheric Clouds with a General Circulation Model, Ph.D. thesis, Johannes Gutenberg-Universität, Fachbereich Physik, http://nbn-resolving.de/urn/resolver.pl?urn=urn:nbn:de: hebis:77-8187, 2005.

Ganzeveld, L. and Lelieveld, J.: Dry deposition parameterization in a chemistry general circulation model and its influence on the distribution of reactive trace gases, J. Geophys. Res., 100, 20 999-21 012, 1995.
Ganzeveld, L., Lelieveld, J., and Roelofs, G.-J.: A dry deposition parameterization for sulfur oxides in a chemistry and general circulation model, J. Geophys. Res., 103, 5679-5694, 1998.

Ganzeveld, L., Lelieveld, J., Dentener, F., Krol, M., and Bouwman, A. J.: Global soil-biogenic $\mathrm{NO}_{\mathrm{x}}$ emissions and the role of canopy processes, J. Geophys. Res., 107, 4298, doi:10.1029/2001JD001289, 2002.

Ganzeveld, L., Aardenne, J., Butler, T., Lawrence, M., Metzger, S., Stier, P., Zimmermann, P., and Lelieveld, J.: Anthropogenic and natural offline emissions and the online EMission and dry DEPosition submodel EMDEP of the Modular Earth Submodel System (MESSy), Atmos. Chem. Phys. Discuss., 6, 5457-5483, 2006,

http://www.atmos-chem-phys-discuss.net/6/5457/2006/.

Hummelshøj, P., Jensen, N., and Larson, S.: Precipitation scavenging and atmosphere-surface exchange, chap. Particle dry deposition to as sea surface, 820-840, Hemisphere Publishing Corporation, Washington, 1992.

Jöckel, P., Sander, R., Kerkweg, A., Tost, H., and Lelieveld, J.: Technical Note: The Modular Earth Submodel System (MESSy) - a new approach towards Earth System Modeling, Atmos. Chem. Phys., 5, 433-444, 2005, http://www.atmos-chem-phys.net/5/433/2005/.

Jöckel, P.: Technical note: Recursive rediscretisation of geoscientific data in the Modular Earth Submodel System (MESSy), Atmos. Chem. Phys., 6, 3557-3562, 2006, http://www.atmos-chem-phys.net/6/3557/2006/.

Olson: World ecosystems (WE1.4): Digital ratser data on a 10 min geographic 1080 x 2160 grid square, edited by: NOAA Natl. Geophsys. Data Cent. Boulder Colorado, global ecosystem database version 1.0: disc a edn., 1992.

Pozzer, A., Jöckel, P., Sander, R., Ganzeveld, L., and Lelieveld, J.: Technical Note: The MESSy-submodel AIRSEA calculating the air-sea exchange of chemical species, Atmos. Chem. Phys. Discuss., 6, 8189-8214, 2006, http://www.atmos-chem-phys-discuss.net/6/8189/2006/.

Pruppacher, H. and Klett, J.: Microphysics of Clouds and Precipitation, 2nd edition, Kluwer, Dordrecht, 954 pp., 1997.

Roeckner, E., Arpe, K., Bengtsson, L., Christoph, M., Claussen, M., Dümenil, L., Esch, M., Giogetta, M., Schlese, U., and Schulzweida, U.: The atmospheric general circulation model ECHAM-4: Model description and simulation of the presentday climate, Tech. Rep. 218, Max-Planck-Inst. für Meteorologie, Hamburg, Germany, 1996.

Slinn, S. and Slinn, W.: Predictions for Particle Deposition on Natural Waters, Atmos. Environ., 14, 1013-1016, 1980.

Stier, P., Feichter, J., Kinne, S., Kloster, S., Vignati, E., Wilson, J., Ganzeveld, L., Tegen, I., Werner, M., Balkanski, Y., Schulz, M., and Boucher, O.: The Aerosol-Climate Model ECHAM5-HAM, Atmos. Chem. Phys., 5, 1125-1156, 2005, http://www.atmos-chem-phys.net/5/1125/2005/.

Stull, R. B.: An Introduction to Boundary Layer Meteorology, Kluwer Academic Publishers, 1988.

Wesely, M.: Parameterization of the surface resistances to gaseous dry depposition in regional-scale numerical models, Atmos. Environ., 23, 1293-1304, 1989.

Wesely, M. and Hicks, B.: A review of the current status of knowledge on dry deposition, Atmos. Environ., 34, 2261-2282, 2000. 